\title{
Correction to: Pre-treatment MRI predictor of high-grade malignant parotid gland cancer
}

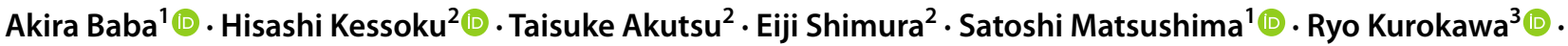

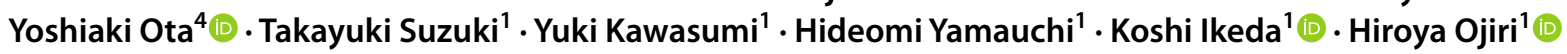

Published online: 4 February 2021

@ Japanese Society for Oral and Maxillofacial Radiology and Springer Nature Singapore Pte Ltd. 2021

\section{Correction to: Oral Radiology https://doi.org/10.1007/s11282-020-00498-z}

In the original publication of the article, one of the reference was missed and the reference is given in this correction.

"Nioche C, Orlhac F, Boughdad S, Reuzé S, GoyaOuti J, Robert C, Pellot-Barakat C, Soussan M, Frouin F, Buvat I. LIFEx: a freeware for radiomic feature calculation in multimodality imaging to accelerate advances in the characterization of tumor heterogeneity. Cancer Res. 2018;78(16):4786-9" by C. Nioche.

The original article has been corrected.

The original article can be found online at https://doi.org/10.1007/ s11282-020-00498-z.

Akira Baba

akirababa@jikei.ac.jp

1 Department of Radiology, The Jikei University School of Medicine and University Hospital, 3-25-8, Nishi-Shimbashi, Minato-ku, Tokyo 1058461, Japan

2 Department of Otorhinolaryngology, The Jikei University School of Medicine and University Hospital, 3-25-8, Nishi-Shimbashi, Minato-ku, Tokyo 1058461, Japan

3 Department of Radiology, Graduate School of Medicine, The University of Tokyo, 7-3-1 Hongo, Bunkyo-ku, Tokyo 113-8655, Japan

4 Department of Radiology, University of Michigan, 1500 E Medical Center Dr, UH B2, Ann Arbor, MI 48109, USA
Publisher's Note Springer Nature remains neutral with regard to jurisdictional claims in published maps and institutional affiliations. 